\title{
A Novel Approach to Rejoin the Carbon Fiber Tow by Fiber Splicing Equipment
}

\author{
Md. Kamruzzaman ${ }^{1, a}$, Md. Eman Talukder ${ }^{1, b}$, Md. Nahid Pervez ${ }^{1,2, c}$, \\ Asif Kamal ${ }^{3, d}$, Ying-Jie CAl ${ }^{1,4, e^{*}}$
}

${ }^{1}$ School of Chemistry and Chemical Engineering, Wuhan Textile University, Wuhan 430073, China

${ }^{2}$ Research institute of flexible materials, School of Textiles \& Design, Heriot-Watt University, Galashiels TD1 3HF, UK

${ }^{3}$ Department of Materials \& Metallurgical Engineering, Bangladesh University of Engineering and Technology, Dhaka 1000, Bangladesh

${ }^{4}$ Hubei Provincial Engineering Laboratory for Clean Production and High Value Utilization of Biobased Textile Materials, Wuhan Textile University, Wuhan 430073, China

anahid01937@yahoo.com, bemant92@gmail.com, cmp58@hw.ac.uk, dasifkamal296@yahoo.com,

eYingjiecai@wtu.edu.cn

${ }^{*}$ Corresponding author

Keywords: Untwisted Carbon Fiber Tow, Fiber Splicing, Uv Light Curing, Epoxy Acrylate Resin.

\begin{abstract}
Carbon fiber tow is used in aerospace, automotive, marine, sports etc. applications with over 20 years' service history due to outstanding processing characteristics. This research work deals with carbon fiber tow mechanical properties improvement by conducting a new device, i.e. fiber splicing equipment to rejoin the untwisted broken carbon fiber tow during weaving procedure with the aid of the application of epoxy resin and UV light mechanism. Furthermore, mechanical properties of carbon fiber tow fabrics were also investigated which included tensile and bursting strength and results showed that significantly improved their properties.
\end{abstract}

\section{Introduction}

Considerable amounts of carbon fibers have been used in recent years for making composites which are used in various load bearing applications such as aircraft, transport, construction, communication and lighting [1-3]. High-performance properties and cost-effective characteristics of carbon fibers enhance these and other emergent applications. Carbon fiber production technology is still in the initial stage, there is a certain gap between the qualities of similar foreign products, resulting in the frequency of adhesion, low shear strength, burr and end breakage of problems occurring in the weaving process more frequently. Carbon fiber tow composites are attractive because of their high stiffness and strength-to-weight ratio [4]. It holds good electrical resistance and better elongation properties but it has low colluding energy and difficult to twist, usually which can't be compared to the natural fiber broken joining by knot or twisting [5]. During weaving process carbon fiber tow breakage appeared due to the tangential friction [6]. In loom tangential friction occurred due to warp stretching and warp-weft threads becoming infected. The traditional method of solving the fiber breakage by manually connecting but it has disadvantages like low efficiency, large knot head and fewer users. So it is not suitable for the connection of the untwisted filament like carbon fiber tow.

In this research work, a novel approach has been presented to reduce the carbon fiber tow breakage in the absence of knot and twist by developing simple fiber splicing equipment (UV Curing mechanism). It facilitates the weaving process by keeping smooth production of carbon fiber without any breakage and mechanical properties of carbon fiber tows were also improved by this device. 


\section{Experimental}

\section{Materials and Method}

$3 \mathrm{~K}$ carbon fiber composite tow sample (Tab. 1) and automatic weaving machine (Jiangyin Tongyuan Textile Machinery, Co. Ltd, China, model SGA598) was used.

Tab. 1 Properties of carbon fiber tow

\begin{tabular}{lllllll}
\hline Specifications & $\begin{array}{l}\text { Density } \\
\left(\mathrm{g} / \mathrm{m}^{2}\right)\end{array}$ & $\begin{array}{l}\text { linear density } \\
(\mathrm{g} / \mathrm{km})\end{array}$ & $\begin{array}{l}\text { Elongation } \\
(\%)\end{array}$ & $\begin{array}{l}\text { Single fiber } \\
\text { diameter }(\mathrm{mm})\end{array}$ & $\begin{array}{l}\text { Intensity } \\
(\mathrm{GPA})\end{array}$ & $\begin{array}{l}\text { Modulus } \\
(\mathrm{GPA})\end{array}$ \\
\hline $3 \mathrm{~K}$ & 1.8 & 198 & 1.9 & 700 & 4.5 & 240 \\
\hline
\end{tabular}

\section{Fabricating Carbon Fiber Tow by Splicing Equipment}

The fabricating method of carbon fiber tow splicing equipment was described in Fig. 1 Carbon fiber tow splicing equipment worked through three major parts. Among them UV light source plate (1) $(60 \mathrm{~mm} \times 30 \mathrm{~mm} \times 6 \mathrm{~mm})$ the top surface of the center line there was two $8 \mathrm{~mm}$ diameter circular light tank, each placed a 5W UV curing light. This UV lamp was a double-crystal parallel, voltage $4.5 \mathrm{~V}$, current $1.4 \mathrm{~A}-1.5 \mathrm{~A}$, wavelength $365-370 \mathrm{~nm}$. UV light source plate and a board equipped with a horn rotating beam hinge connection. UV light source plate (1) of the bottom surface of the transverse centerline of a width of $5 \mathrm{~mm} \times 2 \mathrm{~mm}$ protruding rectangular ridges that was embedded in a rectangular recess curing station $(60 \mathrm{~mm} \times 20 \mathrm{~mm} \times 9 \mathrm{~mm})$ [7]. Curing station of the top surface of the transverse centerline of the transverse width of $5 \mathrm{~mm} \times 3 \mathrm{~mm}$ deep rectangular grooves [4]. When curing lamp plate recessed fitting ridges and curing station, leaving $1 \mathrm{~mm}$ transverse centerline at high rectangular space formed an adhesive bond with the carbon fiber composite tow. UV Light Source plate (1) material was molded by a transparent acrylic plate. Piston plate (9) at the center point of the top surface $8 \mathrm{~mm}$ inner diameter of the circular groove, groove center circle concentric with the center of the rear cover, claw screw rod can be inserted into the round slot. The glue storage groove cover plate (10) and a U type adhesive channel segment (8) were connected by fixed between two parts hinge. Furthermore, rotating the hinge after opening the cover plate (10) removed the piston plate (9) to store the light-cured resin (bisphenol a type epoxy acrylate) in the U-shaped glue storage tank. After adding the piston plate cover plate was closed. After that the preparation process was completed.

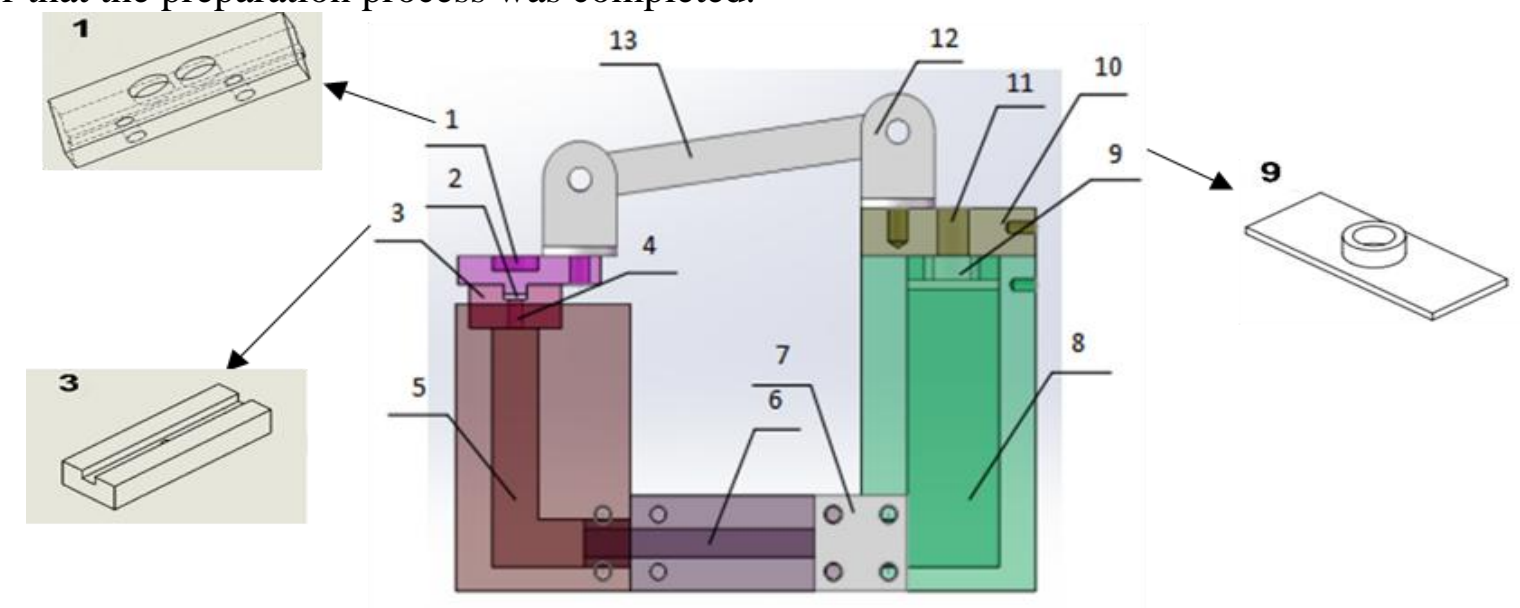

Fig. 1 Schematic diagram of fiber splicing equipment and their different parts, (1) UV light source plate, (2) solidifying slot center/rectangular curing tank (3) Curing station, (4) U type adhesive channel, (5, 6, and 8) U type adhesive channel segment, (7) fixed side pieces, (9) the piston plate, (10) glue storage groove cover plate, (11) screw claw piston rod, (12) hinge connector, (13) rotary beam 


\section{Test Procedure}

Tensile strength of fabric was measured by following ASTM-D-5035(1995) method using Instron tensile tester (Model No. 5565) [8]. The fabric bursting strength was tested using a JH Truburst tester machine according to the BS EN 13938-2 (test area: $10 \mathrm{~cm} 2$, diameter: $35.7 \mathrm{~mm}$ ) testing method [9].

\section{Results and Discussions}

\section{Joining Process of Broken Carbon Fiber Tow Fabric}

At first, by opening the back cover of carbon fiber tow splicing equipment to remove the piston plate for the application of bisphenol epoxy acrylate inside equipment. A typical joining process is presented in Fig. 2 (a) and jointed-without jointed fabric is shown in Fig. 2 (b)-(c). In the period of carbon fiber broken in weaving process [10] two broken carbon fiber tow was passing through heald eye for overlapping of two broken carbon fiber. After that opened the UV light source plate that created rotation in piston rod. For the consequence piston plate transported bisphenol epoxy acrylate, resulting in an appropriate amount of adhesive was passed through the center hole of piston plate to reach curing station. When overlapping broken carbon fiber tow was in the curing tank, UV light source plate reflects UV light on the broken carbon fiber tow. For the consequence piston rod continued to rotate until perfect adhesive was applied on the carbon fiber tow. Moreover carbon fiber splicing equipment was removed to deplete the joining process of broken carbon fiber tow fabric in weaving machine [11].

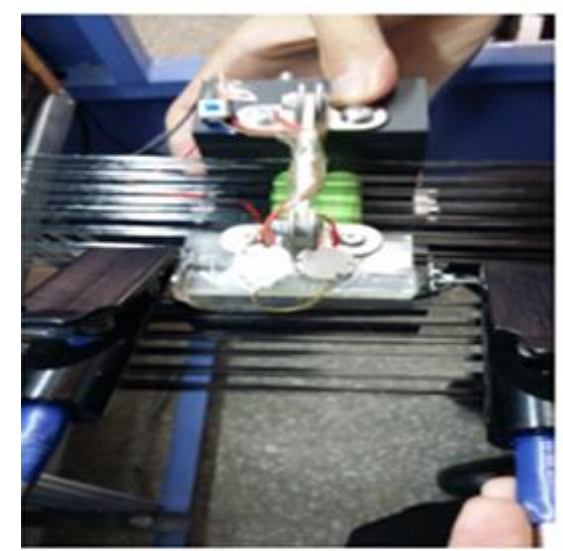

(a)

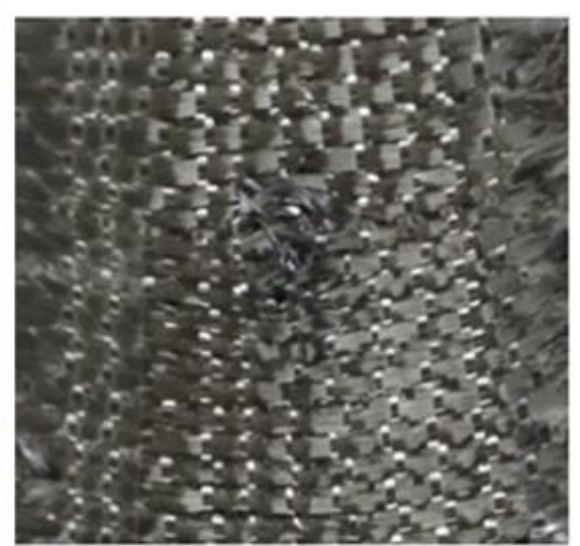

(b)

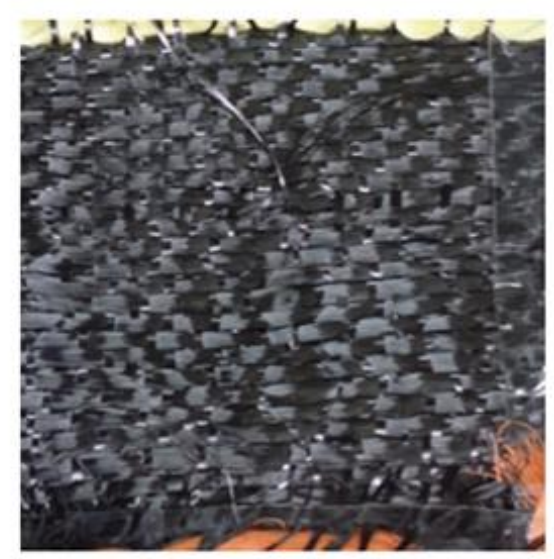

(c)

Fig. 2 (a) Joining process of broken carbon fiber tow fabric (b) Jointed broken carbon fiber tow fabric and (c) Without jointed carbon fiber tow fabric

\section{Tensile Strength Properties}

Tab. 2 presents the average results of tensile strength of jointed broken carbon fiber tow fabric and without joined fabric. The results show that the Jointed carbon fiber tow fabric present higher mechanical properties when compared to the without joined broken carbon fiber tow fabric. The results suggest that the used toughen modifier (epoxy matrix) presented a good compatibility with jointed broken carbon fiber tow fabric. This excellent compatibility has as a rule multiplied the interfacial adhesion between the components and, as a consequence, the tensile property of the jointed samples. Tensile strength outcome attends the necessities for qualification and conformance assurance of the aeronautical industry. According to MEP 15-02224 [12], the medium tensile strength values for composites reinforced with fabric $\left(0 / 90^{\circ}\right)$ are $689 \mathrm{MPa}$. In most cases, the most important potential of use material as reinforcement in composite is that the laminates have 
balanced properties in orientations of $0^{\circ}$ and $90^{\circ}$.

Tab. 2 Tensile strength of carbon fiber tow fabric

\begin{tabular}{lll}
\hline Sample No. & Sample type & Tensile strength (MPa) \\
\hline 1 & Jointed carbon fiber tow fabric & 1155 \\
2 & Without jointed carbon fiber tow fabric & 995 \\
\hline
\end{tabular}

\section{Bursting Strength Properties}

Carbon fiber tow fabric bursting strength after using fiber splicing equipment in weaving process was presented at Tab. 3 Jointed broken carbon fiber tow fabric bursting strength and bursting time was comparatively higher than without joined carbon fiber tow fabric due to application of epoxy resin and UV light from UV light source plate on the broken carbon fiber tow helped to improve the bursting strength performance.

Tab. 3 Carbon fiber tow fabric bursting strength

\begin{tabular}{llll}
\hline Sample No. & Sample type & Bursting strength (MPa) & Bursting time (sec) \\
\hline 1 & Jointed carbon fiber tow fabric & 65 & 27.25 \\
2 & Without jointed carbon fiber tow fabric & 40 & 27.02 \\
\hline
\end{tabular}

\section{Conclusion}

In this study, after incorporated fiber splicing equipment for joining the carbon fiber tow fabric some achievement has been explored in mechanical properties. Joined woven fabric retains higher residual tensile and bursting strength in comparison to without joined fabric due to tow interlacements and the presence of epoxy resin. This presents an interesting challenge in designing woven fabric with interlacements but significantly lower damage. The correlation of these results emphasizes the importance of an adequate combination of polymeric matrix and reinforcement arrangement in the structural composite manufacture, aiming the end use of the processed component.

\section{Acknowledgement}

This work was supported by the China National Textile and Apparel Council (2013 "Textile Vision" Applied Basic Research) a grant from the Hubei Province Science and Technology Support Program (Project 2013BAA043), and the Collaborative Innovation Plan of Hubei Province for Key Technology of Eco-Ramie Industry (E JIAO KE HAN 2014 No.8)

\section{References}

[1] F. Azhari and N. Banthia, Cement-based sensors with carbon fibers and carbon nanotubes for piezoresistive sensing, Cement and Concrete Composites. 34 (2012) 866-873.

[2] D.L. Chung, Carbon Fiber Composites, Butterworth-Heinemann, Boston, MA, USA 1994.

[3] H. Friedlander, L. Peebles Jr, J. Brandrup, and J. Kirby, On the chromophore of polyacrylonitrile. VI. Mechanism of color formation in polyacrylonitrile, Macromolecules. 1 (1968) 79-86. 
[4] K. Knop, Rigorous diffraction theory for transmission phase gratings with deep rectangular grooves, JOSA. 68 (1978) 1206-1210.

[5] P. Pieranski, K. Sandor, D. Giovanni, D. Jacques, et al., Localization of breakage points in knotted strings, New Journal of Physics 3(2001) 10.1-10.13.

[6] S. Adanur, Handbook of weaving, CRC press NY, 2000.

[7] M. Weber, T. Hebrink, T. Nevitt, J. Wheatley, et al., Patent 8469575 B2.(2013)

[8] K. Asfandyar, P. Md Nahid, K. Imran Ahmad, A. Shabeer, et al., New Approach of Phase Change Material Encapsulation through in situ Polymerization to Improve Thermo-Regulating Property of Cellulose, Asian Journal of Chemistry. 28 (2016) 1191-1196.

[9] T. ISO, 13938-2. Textiles-Bursting Properties of Fabrics, Part 2, Pneumatic method for determination of bursting strength and bursting distention. (1999).

[10] J. McAliley, G. Daumit, F. Ethridge, J. Crozier Jr, et al., US Patent US4714642 A.(1987)

[11] M. Naritomi and N. Ando, US Patent 20100151200 A1.(2008)

[12] J. Paiva, S. Mayer, and M. Rezende, Comparison of tensile strength of different carbon fabric reinforced epoxy composites, Materials Research. 9 (2006) 83-90. 